\title{
Excursions
}

Volume 5, Issue 1 (December 2014) Boundaries

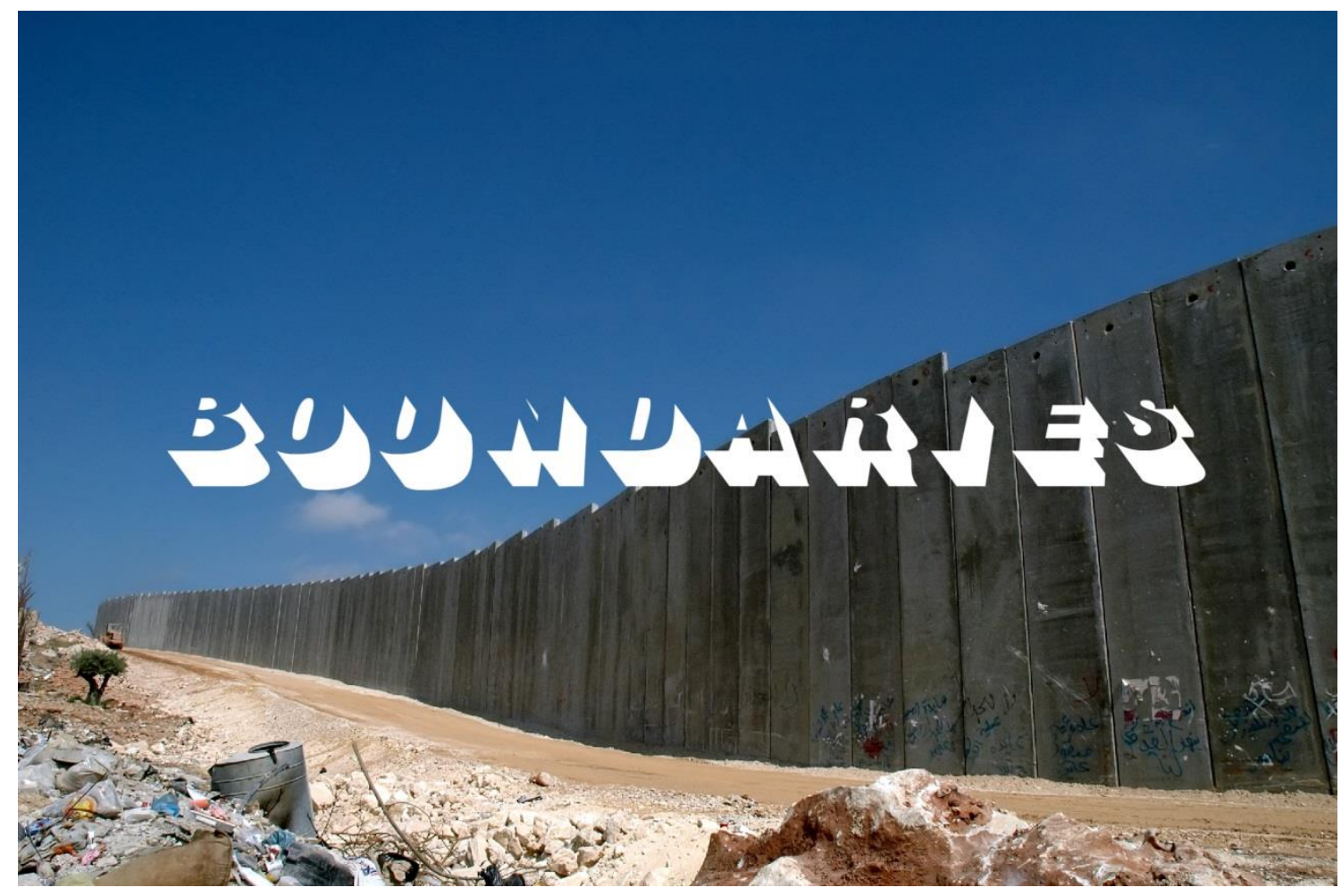

Cover photo: Justin Mclntosh

Cover design: Danny Bright

William Shane Tucker, 'The Jest of the Infinite: Cataloguing the Clôtural Boundaries of Logocentric Totality in David Foster Wallace's Infinite Jest'

Excursions, vol. 5, no. 1 (2014) 
William Shane Tucker

Royal Holloway, University of London

\section{The Jest of the Infinite: Cataloguing the Clôtural Boundaries of Logocentric Totality in David Foster Wallace's Infinite Jest}

Upon publishing the final novel of his American trilogy, Vladimir Nabokov granted an interview with Alvin Toffler for Playboy during which Toffler asked Nabokov if he believed in a higher power. Nabokov responded enigmatically: 'I know more than I can express in words, and the little I can express would not have been expressed, had I not known more' (1964, p.45). Nabokov's answer addressed not only the limit of accessible knowledge but also the limit of accessible knowledge that is capable of being communicated. His statement essentially reflected the ethos of a post-war America suffering from an intense epistemological and ontological scepticism following a waning state of jingoism and ideological certainty that had been thoroughly entrenched in many aspects of American life during World War II (Hoffman, 2005, p.27). This preoccupation would guide the postmodern neo-avantgarde that would go on to dominate the American aesthetic landscape. A significant facet of this fixation was the need to understand and identify the theoretical boundaries between the comprehensible and conveyable knowledge that can be

(C) William Shane Tucker, 2014. License (open-access): This is an open-access article distributed under the terms of the Creative Commons Attribution License, which permits unrestricted use, distribution, and reproduction in any medium, provided the original work is properly cited. No warranty, express or implied, is given. Nor is any representation made that the contents will be complete or accurate or up to date. The publisher shall not be liable for any actions, claims, proceedings, demand or costs or damages whatsoever or howsoever caused arising directly or indirectly in connection with or arising out of the use of this material. 
expressed against the unknowable and/or inexpressible information that could not be encompassed within the boundaries of graspable knowledge.

These theoretical boundaries are treated as an interior/exterior dialectic negotiated through the categories of totality and infinity as well as selfhood and Otherness within the late David Foster Wallace's magnum opus, Infinite Jest (1996). Wallace's work is an eclectic and expansive novel that addresses the limits of informational and referent-based totality by using structural and thematic manifestations of cataloguing - an act contingent on the totality of expressible data as a way of simultaneously adopting and challenging these same boundaries that his postmodern, literary forefathers such as Nabokov attempted to negotiate. In an interview with Anne Marie Donahue, Wallace explained that Infinite Jest explores the 'movement within limits and whether you can puncture the limits or not' (Burn, 2012a, p.71). Set in a satirical future version of America, the work contains a surfeit of plots and sub-plots - including drug-addiction, entertainment, game theory, sports, supernatural encounters, and terrorism - designed to negotiate the boundaries of totality in favour of a 'cohesion-renewing Other' that eludes totalisation (Wallace, 1996, p.384).

It is impossible to completely transgress these boundaries of informational and what will from now on be referred to as logocentric totality (i.e. a component of structuralist philosophy that promotes the epistemological superiority of referentbased signification in language and speech by presuming it to be grounded in a univocal realm of truth). However, Wallace refuses for his work to be completely subservient to these limits. Stephen Burn suggests that Wallace was sceptical of totalised knowledge because he realised the impossibility of cataloguing 'a totality of human data, empathy, and moral honesty' in his work, and that he had 'a metaphysical ache for some kind of meaningful knowledge that lies beyond mortal beings' (2012b, p.9), a knowledge that is incapable of being represented within informational and logocentric totality.

This struggle is the epitome of Emmanuel Levinas's call for allowing the totality of the self to be opened up to the infinite Other - a perpetually absent Other that cannot be conceptualised or expressed within a system of logocentrism without forfeiting its radical alterity in the process (1969, p.51). There is no referent within a system of logocentric totality capable of representing the infinite Other without ontologically - and what Levinas views as unethically - amalgamating the Other into 
the boundaries of the self in order to be understood (1969, p.24). Accordingly, it will be proposed that the tandem negotiation of informational and logocentric totality explored through cataloguing in Infinite Jest can be best understood through a Levinasian mode of analysis.

Levinas was wary about what he perceived as the unethical totalisation of logocentric cataloguing because '[t]he act of "naming" identifies, controls, delimits, and imposes meaning within a fixed totalising system' at the expense of the Other's alterity (Eaglestone, 1997, p.145). As Derrida argues regarding the representation of the Levinasian Other, 'there is no way to conceptualise the encounter: it is made possible by the Other, the unforeseeable "resistant to all categories" [...] The infinitely-other cannot be bound by a concept, cannot be thought on the basis of a horizon' (1978, p.95). Therefore, embarking on a quest of encountering this transcendental Other - eluding the epistemological and ontological boundaries of a logocentric tradition - necessitates embracing a non-comprehensible, nonfoundation of thought.

Despite the problematic nature of such a foundation (or lack thereof), Infinite Jest rests on a liminal ground that maintains as well as fractures the interior/exterior dialectic delineating the theoretical distinction between totality and infinity, and, by extension, the distinction between selfhood and Otherness. As a way of conceptualising the treatment of these theoretical boundaries through acts of cataloguing, the post-structuralist notion of the clotture will be used as a theoretical tool for dissecting Wallace's treatment of said boundaries. Simon Critchley defines the clôture in relation to the Western metaphysical tradition as the 'double refusal both of remaining within the limits of the tradition and of the possibility of transgressing that limit [...] that divides the inside from the outside of the tradition' (1999, p.20). Just as the boundaries of selfhood - like the limits of the cloture - are reliant on the possibility of alterity, Infinite Jest's expansiveness and pseudoproliferation of information becomes subservient to its own Other: the essential nothingness incapable of being articulated through logocentric signification. Although Levinas argues that the Other will always evade full presence and signification due to its 'absolute absence' (1963, p.357), the gaps created by this absence allow for traces of the infinite to emanate within logocentric totality.

When dealing with the high level of abstraction existing beyond the boundaries of logocentric totality, it will be helpful to conceptualise a spatial metaphor capable of 
representing the interior/exterior relationship between the totalised self and the infinite Other. Derrida argues that in order to truly grasp the complicated relationship between totality and infinity, 'it is necessary to state infinity's excess over totality in the language of totality [...] by means of the Inside-Outside structure and by spatial metaphor' (1978, p.112). In 1996 Michael Silverblatt, host of the NPR radio show Bookworm, interviewed Wallace regarding various aspects of Infinite Jest including a narrative structure that Silverblatt found to be fractal-like. Wallace expanded on Silverblatt's suggestion with a description of the geometric form that inspired his writing - the Sierpinski gasket (Fig. 1):

It's actually structured like something called a Sierpinski Gasket, which is a very primitive kind of pyramidical fractal, although what was structured as a Sierpinski Gasket [...] went through some I think 'mercy cuts', so it's probably kind of a lopsided Sierpinski Gasket now. But it's interesting, that's one of the structural ways that it's supposed to kind of come together (Wallace, 1999).

Greg Carlisle's guide to Infinite Jest describes the Sierpinski gasket as being constructed through 'an iterative process of cutting smaller triangle-sized holes out of larger triangles' (2007, p.20). The gasket will be used as an inside-outside spatial metaphor for conceptualising the clotural negotiation of boundaries through Wallace's cataloguing that eschews traditional notions of interiority (totality and selfhood) and exteriority (infinity and Otherness) by inverting the interior/exterior binary. Additionally, D.T. Max mentions that Wallace was drawn to the Sierpinski gasket because he wanted to structure Infinite Jest in a way that was 'self-consciously addictive' (2012, p.183). It will later be suggested that the addictive-oriented structure of the gasket simulates the obsessive-compulsive cataloguing performed by characters within the text.

Furthermore, Wallace's subversion of informational and logocentric totality, by revealing the limitations of cataloguing in Infinite Jest, creates a sense of epistemological hollowness that complements the structure of the Sierpinski gasket. Derrida promotes the idea of locating blind spots, gaps, and interruptions within logocentric systems because the Other cannot be totalised: 'I could not possibly speak of the Other, make of the Other a theme, pronounce the Other as object [...] but for the Other not to be overlooked, He must present' (1978, p.103). Derrida's notion of hollowness allows for traces of the transcendental Other to immanently emanate 
within totality, and this is symbolically accentuated by the gaps of negative space fostered when zooming in on the Sierpinski gasket to reveal an infinite chain of selfsimilar shapes that progressively inserts hollowed-out space within the structure. Hering also notes the importance of absence in Infinite Jest and how it connects back to the Sierpinski gasket:

Wallace's deliberate obfuscation of straight answers to the principle enigmas of the novel reminds the reader that they are regarding a schema characterized as much by absence as by presence and if we look again at the Sierpinski gasket, we may note that each configuration of three triangles is also accompanied by the apparent visible absence of another triangle (2010, p.91).

The epistemological gaps purposely imposed through cataloguing will be treated as hollowness within totality allowing for traces of the Other's alterity to emerge.

Recognising how Wallace conceptualises the nature of totality and infinity is useful in order to understand how he negotiates these boundaries in Infinite Jest. Wallace explores the nature of infinity as a hybrid abstract-tangible entity in his mathematical text, Everything and More: A Compact History of Infinity (2003). Wallace begins by addressing the problematic existence of abstractions and how they elude conceptualisation: 'In what way do abstract entities exist, or do they exist at all except as ideas in human minds [...] what is the ontological status of mathematical entities and relations?' (2003, p.20). In a notion related to Levinas's appeal for respecting the radical alterity of the Other that cannot be totalised, Wallace suggests that mathematics and metaphysics foster abstract thoughts allowing individuals to 'conceive of things that we cannot, strictly speaking, conceive of' (2003, p.22). Here Wallace is playing with the validity of the boundaries dividing the knowable and conveyable knowledge of totality from the incomprehensible essence of the infinite. Wallace's contention that mathematical and metaphysical abstraction makes it possible to weaken, albeit not destroy, such boundaries complements the liminal nature of the clôture that simultaneously attempts to reinforce and transgress said limits.

Moreover, Roberto Natalini argues that among the central problems in Infinite Jest and Everything and More is this inability to master infinity, which prevents Wallace from being able to 'escape the vicious circle of infinite regress to reach a more stable knowledge' because he is trapped within the 'infinite circularity of word problems' arising from the necessity of having to use imperfect referent-based 
signifiers (2013, p.44). Since Wallace can never transgress the boundaries of totality, he pursues a clôture of totality and infinity through a paradoxical act of immanence similar to the function of the Sierpinski gasket: 'To overcome this kind of paralysis, Wallace looks toward the other kind of mathematical infinity - with limits, convergence, asymptotes, and so on - to go beyond our standard boundaries' (Natalini, 2013, p.48). The notion of both immanently and transcendentally overcoming these boundaries is explored in Infinite Jest.

For example, the clotural negotiation of the interior/exterior dialectic can be thematically identified in the diverging perspectives between tennis coach Gerhardt Schtitt and Québécois terrorist Remy Marathe. Interestingly, Wallace makes the decision for these two non-native English speaking characters - Schtitt is a German expat and Marathe is a native French speaker - to be best able to identify and communicate in English the logocentric and ontological boundaries between totality and infinity that are so difficult to articulate. In a notion complementary to Wallace's fascination with the infinite recursion occurring within the bound Sierpinski fractal, Schtitt views the goal of tennis - and by extension life - as being driven by the need to internally negotiate the boundaries of the self:

Cantorian and beautiful because infoliating, contained, this diagnate infinity of infinities of choice and execution, mathematically, uncontrolled but humanly contained, bounded by the talent and imagination of self and opponent, bent in on itself by the containing boundaries of skill and imagination that brought one player finally down, that kept both from willing, that made it, finally, a game, these boundaries of the self (1996, p.82, emphasis in the original).

Like the internal recursion of the Sierpinski gasket, the boundaries of the tennis court can be negotiated by what Schtitt promotes as an 'infinite expansion inward' (1996, p.83). Schtitt argues that tennis is not 'reducible to delimited factors' but instead like the simultaneous rejection and incorporation of totality by the cloture possesses a "not-order [...] the place where things broke down, fragmented into beauty' (1996, p.81, emphasis in the original). The tennis player must accept remaining in these boundaries while also seeking an immanent transcendence of them by learning to cultivate an infinite experience on a bound plane. Schtitt's focus on the 'transcendence of self' is a form of 'self-forgetting' (1996, p.635) that paradoxically breaks the confines of the solipsistic self through an introspective movement into the self. 
Schtitt's endeavour to immanently negotiate the boundaries of selfhood by journeying into the self is juxtaposed against its antithesis: an external transcendence of solipsistic boundaries. In a lengthy philosophical discussion with O.N.A.N. field operative Hugh Steeply, Marathe discusses the importance of transcending the confines of the self. He argues that the self must recognise that 'Our attachments are our temple, what we worship' and that the individual must therefore escape this selfimposed temple by worshipping 'Something bigger than the self' (1996, p.107). Burn suggests that Wallace associated these self-imposed temples with solipsism because 'emerging out of the pursuit of pleasure is a logic of self-interest that denies the existence of the Other' (2012b, p.11). Furthermore, Steeply's employment with O.N.A.N. constitutes being trapped within a temple as the name alludes to the selfindulgence of onanism. In the Book of Genesis (38:9), Onan was slain by God for spilling his 'seed' on the ground rather than impregnating Tamar. In terms of Levinasian ethics, this act prevented Onan from producing a tribe of descendants potentially infinite in size, and thus by spilling his seed Onan's mortality effectively became an unethical, self-imposed totality. While Marathe's call for selftranscendence by breaking free of solipsistic, self-imposed boundaries is opposed to Schtitt's call for self-immanence by learning to function within those boundaries, both positions attempt to negotiate the boundaries between the self and Other.

The interior/exterior negotiation of the self's boundaries as a clôture is relevant to how informational and logocentric totality are addressed within Infinite Jest through acts of cataloguing. In a series of satirical attempts at cataloguing data within the novel in order to show how instances of cataloguing information 'prove empty and futile exercises' (Burn 2012b, p.28), Wallace attempts to undermine the totalising nature of referent-based signification in favour of a perpetually absent Other eluding representation. However, his ultimate inability to completely eschew the necessity of logocentric referents in his text helps emphasise the clôtural nature of Infinite Jest.

For example, endnotes are present throughout Wallace's oeuvre as a way for him to elaborate on aspects of his text while self-consciously challenging the validity of his notions. Despite the impossibility of transcending the physical boundaries of the main narrative, Infinite Jest attempts to utilise 388 endnotes appearing in the section titled 'Notes and Errata' as a way of structurally undermining the totality of its content. The endnotes within Infinite Jest, ranging in role from short expository addons to full-fledged narrative passages, simultaneously fracture and marginalise the 
main narrative as much as they support and synthesise it. In this sense the endnotes are a subversion of the text through sub-versions of the text.

The disorder Wallace creates through his endnotes supports Levinas's notion in Totality and Infinity that the very framework of thought would be destroyed if totality were to be exceeded: 'To contain more than one's capacity does not mean to embrace or to encompass the totality of being in thought [...] To contain more than one's capacity is to shatter at every moment the framework of a content that is thought' (1969, p.27). Wallace plays with this notion of exceeding the capacity of an epistemological framework by subverting the totality of the main narrative through sub-versions of the narrative in his endnotes. One particular example of the expansive, narrative endnote occurs during the episode where tennis players are engaged in a game of Eschaton: a children's game in the form of a nuclear war simulation where teams are separated into opposing countries to battle on a global map drawn upon the surfaces of multiple tennis courts.

Not only does the endnote clarify the mathematical intricacy of Eschaton by providing an extensive, albeit slightly erroneous, summary of the mean-value theorem, it is also noteworthy because the character Michael Pemulis appears to break the boundaries of the main narrative in order to supplant the narrator in the endnote. The endnote begins with 'Pemulis here, dictating to Inc, who can just sit there making a steeple out of his fingers and pressing it to his lip and not take notes and wait and like inscribe [sic] it anytime in the next week and get it verbatim, the smug turd' (1996, n.123, p.1023, emphasis in the original). The use of sic notation here is interesting because it suggests that the protagonist, Hal Incandenza, is inscribing Pemulis's words within the endnote, essentially making him the narrator of the narrator; inscription is even more significant to the nature of clottural boundaries considering how the mathematical definition of inscription designates a process of drawing a geometric figure within another figure so that the vertices of the enclosed figure touch the outer figure but can never exceed the outer figure.

The endnote suggests that these two characters have been able to ontologically escape the confines of narrative totality in the main text. This notion is further problematised by Pemulis's explanation, along with Hal's edits, of the mean-value theorem's complexity related to delimited boundaries: 'This is wicked. This is fucking elegant. Note that $[\ldots]$ you can use this Mean-Value time-saver with anything that varies within a (definable) set of boundaries and whatnot' (1996, n.123, p.1024, 
emphasis in the original). In a meta-treatment of this explanation, the passage's inclusion of these two characters eschews the definable boundaries necessary for the theorem by obfuscating the limit between the main narrative and the endnotes. Pemulis, a supporter of the Allston High School Wolf-Spiders, closes the section under the presumed supervision of Hal:

It's going to be interesting to see if [sic] Hal, who thinks he's just too sly trying to outline Eschaton in the 3rd-person tense [sic] like some jowly old Eschatologist with leather patches on his elbows [sic], if Inc can transpose [sic?] the math here without help from his Mumster. Later.

P.S. Allston Rules 1996, n.123, pp.1024-25, emphasis in the original).

In an instance of postmodern meta-trickery through the technique of the frame narrative, Hal and Pemulis are able to negotiate the boundaries of their roles as subservient characters in order to become narrators themselves in the endnotes. This act effectively undermines the delimited totality of the main narrative by demonstrating that a liminal, ontological space exists for characters outside the boundaries of the main narrative.

The relation of cataloguing to totality is also thematically explored within the text by the characters themselves. The psychological angst and loneliness experienced by characters such as $\mathrm{Hal}$ and Kate Gompert results from them experiencing a disconnect between words and the objects they wish to catalogue; language effectively supplants the reality that the characters wish to express. This is reflected in the text's treatment of anhedonic depression:

The anhedonic can still speak about happiness and meaning et al., but she has become incapable of feeling anything in them, of understanding anything about them, of hoping anything about them, or of believing them to exist as anything more than concepts. Everything becomes an outline of the thing. Objects become schemata. The world becomes a map of the world (1996, p.693).

The final sentence alludes to Jorge Luis Borges's micro-story, 'On Exactitude in Science' (1999, p.325). In the story skilled cartographers construct a map that is so large and detailed that it supersedes the physical territory of the Empire it is supposed to represent. Essentially, the process of cataloguing the territory ends up perverting the territory's authenticity entirely. 
Likewise, the totalising effects of logocentric referents are challenged by the anhedonic conditions of Kate and Hal. These states are partly caused by both characters realising that cataloguing internal feelings through these referents ultimately leads to a constructed truth that further alienates them by effectively creating blind spots of alterity within their selfhood. Marshall Boswell notes that 'whenever the characters invest meaning in things - that is, in referents rather than in the interactive production of functional signification - they inevitably succumb to loneliness and solipsism' (2003, p.40). Both characters' sense of anhedonic emptiness - what can be symbolically represented as a negative space within their Sierpinski gaskets of selfhood - results from them being unable to properly catalogue their feelings as they exceed the signifying capabilities of logocentric referents by residing in the realm of the infinite.

For example, Kate Gompert's crippling depression is exacerbated by her inability to effectively communicate her inner turmoil to others because it is 'indescribable', and this causes her depression to be 'lonely on a level that cannot be conveyed' (1996, p.695). In an episode towards the beginning of the novel Kate is being interviewed by a doctor who believes that a major reason for Kate's depression is her inability to communicate the extent of her existential alienation. Aware of the semantic limitations of referent-based signification, Kate is resigned to simply respond, 'That's what you guys want to call it, I guess' (1996, p.73). She later addresses the fact that it is impossible to categorise her depression - and therefore communicate the complete extent of her inner state - without necessarily betraying its authenticity. She claims, 'I don't know what I could call it. It's like I can't get enough outside it to call it anything' (1996, p.73, emphasis added). Just as the clôture challenges boundaries yet is incapable of complete transgression, Kate is ultimately trapped within the boundaries of a selfhood that is completely foreign to her.

Hal's anhedonic alienation has even more significant implications. His anhedonia is partially caused by the realisation that despite being a lexical prodigy who can 'recite great chunks of the dictionary, verbatim, at will' (1996, p.317), he is unable to locate a referent capable of representing his feelings, and he therefore perverts the authenticity of his self when attempting to catalogue those feelings. Hal feels he lacks 'bona fide intensity-of-interior-life-type emotion' because in Lacanian terms he believes that those feelings are ultimately linguistic constructs of the Symbolic Order detached from the Real, which cause Hal to view his selfhood as containing 'pretty 
much nothing at all' (1996, p.694). Hal of course is capable of feeling, but he fears that expressing these feelings through logocentric referents would 'tear them from the prelinguistic Real that is his interior and transport them into the alienated world of textuality' (Boswell, 2003, p.150). Hal fears that allowing this to happen would decimate his selfhood.

Prior to Hal's degenerative mind-body schism, he catalogues as a way of situating the boundaries of his selfhood without realising the limitations of logocentric referents and informational totality. For example, while sitting in a waiting room he attempts to provide an exhaustive list of all of the blue-coloured objects that are in his view: blue shapes in the shag carpet, two plush chairs, lamps, some of the magazine covers, the wallpaper, window sills and crosspieces, a 'nautical-blue border of braid' around Pemulis' yachting cap, the slices of blue sky visible in photographs of students, a chaise, the fingertips and lips of Alice Moore, Avril's pen, etc. (1996, pp.508-9). He also attempts to categorise individuals around the stimuli such as the character Trevor Axford 'about whom there was today not even a hint of the color [sic] blue' (1996, p.510). However, what Hal does not realise is that the totalised cataloguing of the colour blue is an impossible task that can never be exhaustive when factoring in the likely infinitesimal blue objects in the room that would require cataloguing. Furthermore, his negotiation of Axford's selfhood in accordance with the cataloguing of the blue objects would be in Levinasian terms an unethical appropriation of Axford's alterity by marginalising the sovereignty of his selfhood.

This episode can be juxtaposed against the first episode of the novel, that functions proleptically as the final episode of the narrative. The episode begins in a similar manner to the previous episode with Hal sitting in an administration office, but this time at the University of Arizona with his uncle Charles Tavis and tennis coach Aubrey deLint while being interviewed by the deans of admissions, athletics, and academic affairs. Hal has already experienced the psychological trauma leading to his mind-body schism, so when he attempts to catalogue the objects and people within the office he is - by contrast to the previous episode - unable to speak, let alone articulate a concrete sense of selfhood in order to guide him. The novel opens with the following passage:

I am seated in an office, surrounded by heads and bodies. My posture is consciously congruent to the shape of my hard chair. This is a cold room in University 
Administration, wood-walled, Remington-hung, double windowed against the November heat, insulated from Administrative sounds by the reception area outside, at which Uncle Charles, Mr. deLint and I were lately received [...] I am in here (1996, p.3).

While the passage appears to promote Hal's strong sense of selfhood, he is also unable to use language in order to communicate with the outside world.

For example, after Hal raises the concerns of his interviewers by displaying animal-like characteristics when attempting to communicate, he is then rushed to the hospital while exhibiting what is ultimately a useless lexical prowess by thinking, 'There are, by the O.E.D. VI's count, nineteen nonarchaic synonyms for unresponsive, of which nine are Latinate and four Saxonic' (1996, p.17, emphasis in the original). As a result of not only being isolated in a 'cold room' but also being isolated from the people around him due to being unable to communicate, Hal is effectively placed within a 'spatial metaphor for the hermetic husk of a self' (Burn 2012b, p.46) similar to the hollowed-out structure of the Sierpinski gasket. The true essence of Hal incapable of being recorded within the novel - is the Other juxtaposed against the hard data capable of being catalogued in the room. Burn argues, 'The novel's opening, then, sets up a tension between an excess of information and unexplainable selfhood that is elaborated throughout the rest of the book' (2012b, p.46). Infinite Jest thus reveals the impossible task of attempting to catalogue and understand the notion of a fractured selfhood that cannot be recorded.

The need for certain characters to totalise data through obsessive cataloging also accentuates the text's preoccupation with the nature of addiction as 'Wallace shows their cataloguing to be indicative of a deeper lack of control' (Burn, 2012b, p.28). In what would function as a comical allusion to this addictive practice, Wallace's posthumous novel The Pale King (2011) includes a passage involving a young boy who attempts the 'unimaginable challenge' of 'press[ing] his lips to every square inch of his own body' (2011, p.396). This practice is essentially an attempt to catalogue his anatomy in its totality. Interestingly, the boy's chiropractor maintains a philosophy that is wholly relevant to the Levinasian totality/infinity dialectic: 'the interpenetrating dance of spine, nervous system, spirit and cosmos as totality - in the universe as an infinite system of neural connections that had evolved was the universe's way of being accessible to itself' (2011, pp.405-406, emphasis added). The 
desire for the self to unethically impose order on alterity through instances of obsessive-compulsive cataloguing is further addressed in Infinite Jest.

While some instances of addictive cataloguing are innocuous, such as the character Rodney Tine Jr. measuring the length of his penis every morning or Don Gately's stepfather meticulously recording the daily amount of drinks he consumes, there are also far more nefarious examples that attempt to supplant alterity. An example of totalising, obsessive-compulsive cataloguing occurs when Hal's brother, Orin, meticulously catalogues his sexual encounters with women to the point of totalising the autonomy of their respective selfhoods by categorising them as 'Subjects' (1996, p.43). In what would certainly be an ironic gesture in relation to the dichotomy of totality and infinity, Orin traces lemniscates - or 'little sideways 8's' on the 'postcoital flanks' of his totalised Subjects (1996, p.289). The lemniscates as totalising gestures mock Levinas's call for respecting infinite alterity by instead symbolising the apprehension of the women's autonomy after they are categorised as Subjects through Orin's sexual cataloguing.

This unethical form of addictive cataloguing is also apparent when Steeply recounts the obsessive cataloguing his father would engage in when watching episodes of the television show $M^{*} A^{*} S^{*} H$. Steeply's father began watching the show every Thursday after work, but the syndication of the television show on multiple stations turned his regular habit into a crippling compulsion. As reruns of previous episodes began appearing more often, Steeply mentions that his father started taking notes in a small notebook while watching $M^{*} A^{*} S^{*} H$ (1996, p.641). The father's obsessive cataloguing of the episodes reaches its apex when he begins to believe that there are secret messages inserted into the episodes that can be decoded. His cataloguing then becomes unethically totalising as he begins categorising facets of reality in order to conform to $M^{*} A^{*} S^{*} H$. It begins with him imposing fictional locations from the show onto actual locations by referring to places like the kitchen as the 'Mess Tent' and his den as the 'Marsh or Swamp' (1996, p.642). More problematically, he writes letters to the actors in $M^{*} A^{*}{ }^{*} H$ but addresses the name on the envelopes to the characters that the actors played on the show. For example, he writes letters to the actor Maury Linville but addresses them to his character, Major Burns, and he mails them 'not c/o Fox Studios or whatever, but addressed to an involved military address, with a Seoul routing code' (1996, p.643). Steeply's father is effectively marginalising the alterity of the actors so that they conform to the 
$M^{*} A^{*} S^{*} H$-based reality he wishes to impose. The alterity and information that Orin and Steeply's father unethically totalise through cataloguing is a practice Wallace sought to avoid implementing within his work but was unable to completely eschew.

Whether it is through the cataloguing of information in the endnotes or the categorising undertaken by obsessive-compulsive characters, Infinite Jest attempts to use the nature of cataloguing as a way of negotiating the clotural boundaries between the data that is known and capable of being expressed through logocentric referents against the unknown and non-conveyable. Like Nabokov, Wallace was never able to transcend these boundaries nor pinpoint a referent capable of representing the infinite Other, but this should not be considered a failure: his dissent against logocentrism promotes the presence of blind spots within Infinite Jest, allowing for the Other's trace to emanate. As related through the interior/exterior duality of the Sierpinski gasket, the clottural negotiation of these boundaries - by being paradoxically conceptualised as a form of immanent transcendence or transcendental immanence - efficaciously embraces, enmeshes, inverts, subverts, and ultimately obscures these limits between the totalised self and infinite Other in what effectively becomes the jest of the infinite within Infinite Jest. 
Images

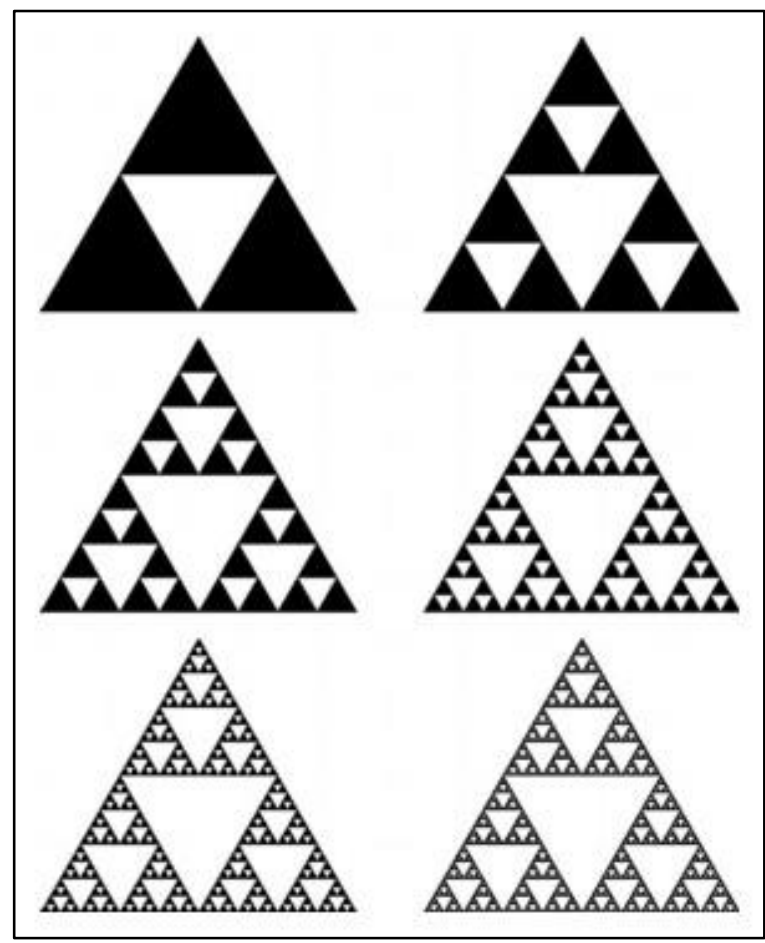

Fig. 1. The iteration of the Sierpinski gasket. Image provided by The Joint Policy Board for Mathematics. 


\section{Bibliography}

Borges, J.L., 1999. On Exactitude in Science. Collected Fictions. Trans. A. Hurley. London: Penguin. p.325.

Boswell, M., 2003. Understanding David Foster Wallace. Columbia: University of South Carolina Press.

Burn, S., 2012a. Conversations with David Foster Wallace. Jackson: University Press of Mississippi.

2012b. David Foster Wallace’s 'Infinite Jest': A Reader's Guide. 2nd ed. New York: Continuum Publishing.

Carlisle, G., 2007. Elegant Complexity: A Study of David Foster Wallace's Infinite Jest. Los Angeles: SSMG Press.

Critchley, S., 1999. The Ethics of Deconstruction. Edinburgh: Edinburgh University Press.

Derrida, J., 1978. Writing and Difference. Trans. A. Bass. London: Routledge.

Eaglestone, R., 1997. Ethical Criticism: Reading After Levinas. Edinburgh: Edinburgh University Press.

Hering, D., 2010. Consider David Foster Wallace: Critical Essays. Los Angeles: SSMG Press.

Hoffmann, G., 2005. From Modernism to Postmodernism: Concepts and Strategies of Postmodern American Fiction. Amsterdam: Rodopi.

Levinas, E.,1969. Totality and Infinity: An Essay on Exteriority. Trans. A. Lingis. Pittsburgh: Duquesne University Press.

1986. The Trace of the Other. M. Taylor, ed. trans. A. Lingus. Deconstruction in Context: Literature and Philosophy. Chicago: University of Chicago Press. pp. 345-359. 
Max, D.T., 2012. Every Love Story is a Ghost Story: A Life of David Foster Wallace. New York: Viking Adult.

Nabokov, V., 1964. Playboy Interview: Vladimir Nabokov. Interviewed by A. Toffler. Playboy, Jan 1964, pp.35-45.

Natalini, R., 2013. David Foster Wallace and the Mathematics of Infinity. M. Boswell and S. Burn, eds. A Companion to David Foster Wallace Studies. New York: Palgrave Macmillan. pp.43-58.

Wallace, D.F., 2003. Everything and More: A Compact History of Infinity. New York: W. W. Norton \& Company. 1996. Infinite Jest. New York: Little, Brown and Company. 1999. Interview on Bookworm. Interviewed by M. Silverblatt. [Radio] KCRW, 12 August 1999. 2011. The Pale King. London: Penguin. 